ISSN: 2146-3042

DOI: $10.25095 /$ mufad.756303

\title{
Finansal Yatırım Kararında Duygusal Faktörlerin Rolü: Bir Literatür Taraması*
}

\author{
Naime USUL*
}

\section{$\ddot{O Z Z E T}$}

Modern finans teorisine göre yatırımcılar yatırım kararlarını verirken piyasa bilgisine eksiksiz sahip olup, bu bilgiyi doğru analiz edip, sonuç olarak beklediği faydayı maksimize edecek şekilde karar verir. Bu fayda riske göre getiridir. Dolayısı ile temel varsayımı "rasyonel yatırımcılar" ve "beklenen fayda teorisi" olan bu bakış açısı, yatırımcının belli bir riske göre getirisini maksimize edecek yatırım kararını vereceğini öngörür. Davranışsal finans ise yatırımcıların getiri ve risk dişında başka faktörlerden de etkilenebileceğini, bu sebeple rasyonellikten, hem mikro seviyede birey olarak hem de makro seviyede piyasalar etkileyecek şekilde sapabileceğini savunur. Bu çalışma, irrasyonel yatırımcı davranışlarıla ilgili literatüre genel bir bakış atıp, özellikle duygusal faktörlerin etkisine dikkat çekerek "duygu hevristiği” ve yatırım kararına olan etkisi ile ilgili yeni çalışmaları desteklemeyi hedeflemektedir. Nispeten bakir olan bu alanda, disiplinler arası bakış açısıyla, psikoloji, sosyoloji ve pazarlama gibi diğer sosyal bilimlerden de katkı alarak yeni çalışmalar yapılmasının, yatırım kararlarında duygusal faktörlerin etkisinin anlaşılması açısından faydalı olacağı öngörülmektedir.

Anahtar Kelimeler: Davranışsal Finans, Etkin Piyasa Hipotezi, Yatırım Kararı, Yatırımcı Davranışı, Duygu Hevristiği.

JEL Sınıflandırması: G40, G41, G11, M14.

The Role Of Affective Factors In Financial Investment Decision: A Literature Review ABSTRACT

Modern finance theory assumes that investors have complete information about the financial markets, they analyze this information correctly and invest accordingly. That is, the traditional point of view, which bases its arguments on the "rational investors" and the "expected utility hypothesis", suggests that investors will maximize their expected return with respect to risk. Behavioral Finance, on the other hand, suggests that investors might be influenced by other factors as well and may deviate from rationality. This study aims to support new studies concerning "affect heuristic" and its effect on the investment decision, first by addressing to the literature about irrational investor behavior and then by highlighting the influence of affective factors on investment decision. It is asserted that new studies in this field, which adopts an interdisciplinary point of view by incorporating other social sciences will be beneficial in understanding the implications of affective factors in terms of investment behavior.

Keywords: Behavioral Finance, Efficient Market Hypothesis, Investment Decision, Investor Behavior, Affect Heuristic

Jel Classification: 640, G41, G11, M14.

* Makale Gönderim Tarihi: 27.09.2019, Makale Kabul Tarihi: 03.12.2019, Makale Türü: Literatür Taramas1

* Öğr. Gör. Dr., Çankaya Üniversitesi, naime@cankaya.edu.tr, ORCID ID: 0000-0002-8475-9887. 


\section{GİRIŞ}

Geleneksel finans bir sosyal bilim dalı olmasına karşın, bireylerin insani özelliklerini, algısını, psikolojisini, sosyalliğini ve tüm bunların neden olabileceği önyargı ve yanılsamaları teorilerin dışında tutmuş; insanın "homo economicus" diye tabir edilen yüzde yüz rasyonel bir varlık olduğu varsayımıyla çalışmıştır. Buna ek olarak, bireylerin risk algısı ve piyasaların yapısı ile ilgili de ciddi varsayımları olan geleneksel finans teorileri, gerçek piyasalardaki yatııım davranışlarını ve buna bağlı piyasa hareketlerini açıklamakta yetersiz kalınca ortaya geleneksel teorilerin öngöremediği "anomaliler" ortaya çıkmıştır. Davranışsal finans; psikoloji, sosyoloji ve pazarlama gibi farklı disiplinlerden de katk1 alarak bu anomalileri açıklamaya ve anlamaya çalışan nispeten yeni ve gelişmeye açık bir alandır. Kahneman ve Tversky'nin 1981 tarihli karar verme literatüründe çığır açan çalışmasıyla, bireylerin duygu ve düşüncelerine ek olarak, bir problemin kelimelere dökülüşs şeklinden dahi etkilendikleri ortaya konulmuştur. Aynı problemin, aynı bilgiyi ve veriyi içeren fakat farklı kurulmuş iki versiyonunda dahi ortaya çıkan karar değişiyorsa, yatırım kararı gibi kompleks kararlarda bireylerin getiri ve risk dışında hiçbir faktörden etkilenmeden tamamen rasyonel bir karar verdiğini varsaymak çok gerçekçi olmayacaktır. Dolayısı ile, bu çalışmadan sonra çeşitli alanlarda bireylerin karar mekanizmaları sorgulanmış ve çalışılmışıtır. Bu alanlardan birisi de finansal kararlardır.

$\mathrm{Bu}$ makalede öncelikle geleneksel finansın yatırım kararına olan bakış açısına ve bu bakış açısının temel varsayımı olan Rasyonel Beklentiler Teorisi'ne değinilecek, sonrasında davranışsal finansın ortaya koyduğu anomalilere ve bunlara getirdiği açıklamalara yer verilecektir. Hali hazırda literatürde davranışsal finansın anlaşılması üzerine derlemeler ve literatür taramaları kısıtlı olsa da mevcuttur. (Bknz: Taner ve Akkaya, 2005; Aytekin ve Aygün; 2016). Bu çalı̧̧mada farklı olarak, davranışsal finans alanı için genel bir çerçeve çizildikten sonra, duygusal faktörlerin insanın karar mekanizmasındaki yeri anlatılacaktır. Bu bağlamda, literatürde "hevristik (heuristic)" diye tabir edilen zihinsel kısa yollara ve bilişsel önyargılara da değinilecektir. Fakat son yıllarda öne çıkan ve henüz üzerinde yeterince çalışılmamış duygu temelli bir zihinsel kısa yol olan "duygu hevristiği (affect heuristic) ${ }^{2}$ ", üzerinde özellikle durulacak ve bu yeni hevristik okuyucuya tanıtılacaktır. Yeni araştırmalara aç ve bakir bir alan olan bu zihinsel kısa yol ve yatırımcı üzerindeki etkileri tartsşllarak konu ile ilgili yeni çalışmalara bir temel oluşturmak hedeflenmiş̧ir.

\section{RASYONEL BEKLENTILER TEORISI}

Klasik iktisat teorisinin temelini oluşturan rasyonellik varsayımı rasyonel bireylerin, kendisini bağlayan bütün piyasa kısıtlarını ve elindeki bilgiyi göz önünde bulundurarak Bayes istatistiği prensipleri ile tercihlerini maksimize edeceğini öngörür (McFadden vd. 1999: 76). Dolayısı ile rasyonel birey tüketim, üretim, yatırım ve bunun gibi kararlarında Herb Simon'un (1986) söylediği gibi en iyisinden azına razı olmayacaktır.

\footnotetext{
${ }^{1}$ Türkçesi zihinsel veya bilişsel kısa yol şeklinde çevrilmekle beraber literatürde hevristik olarak kullanıldığı görülmektedir (Bknz: Sezer ve Demir, 2015:69,72; Tomak, 2009: 145-163; Kahyaoğlu,2011: 33; Bayazıt Hayta, 2014: 329; Onur ve Kırıkçı, 2018: 4545; Altınöz ve Altınöz, 2016:21; vb.).

${ }^{2}$ Affect heuristic teriminin Türkçe bir karşıllığ literatürde bulunmamakla beraber duygu temelli zihinsel kısa yol anlamına gelmektedir. Hevristik teriminin hali hazırda kullanılıyor olmasına istinaden "duygu hevristiği" şeklinde çevrilmiştir.
} 
İlk defa Muth tarafindan 1961 yılında mikro iktisat kontekstinde formüle edilen rasyonel beklentiler prensibi daha sonra çeşitli bilim insanlarının da ilgi odağı olmuş ve Lucas, Sargent, Kydland, Prescott ve diğerleri tarafindan çalışılmıştır. Böylelikle birçok iktisat teorisinin temelini oluşturan "Beklenen Fayda Teorisi" ortaya çıkmıştır. Buna göre, önünde alternatif seçenekleri bulunan rasyonel bir birey, maruz kaldığı kısıtları göz önünde bulundurarak, kendi faydasını belli değişkenlere göre maksimize eder. Markowitz literatüre sunduğu optimal portföy seçimi tarifinde, aynı bakış açısıyla, maksimize edilecek faydayı finansal getiri , kısıt olarak da riski belirlemiş̧tir. Bu demek oluyor ki rasyonel bir yatırımcı riske göre getirisini maksimize etmelidir.

Rasyonel beklentiler teorisi, Sharpe (1963) ve Lintner (1965) tarafindan geliştirilen sermaye varlıklarını fiyatlama modeli ve Fama (1970)'nın öne sürdüğü etkin piyasalar teorisi gibi modern finansın ana teorilerinin de temelini oluşturur. Fama'nın rasyonel yatırımcıyı baz alarak sunduğu Etkin Piyasalar Hipotezi'ne göre rasyonel yatırımcının rasyonel beklentiler ile Bayes kurallarına göre vermiş olduğu yatırım kararları sayesinde piyasadaki finansal enstrümanların fiyatları kendi teorik (içsel) değerlerini yansıtmış olur (Barberis ve Thaler, 2003:1056). Optimal karardan hata ile sapan bireyler olsa dahi, rasyonel yatırımcilar ortaya çıkan arbitraj firsatını hemen değerlendirirler ve fiyat yanlışlığı anında düzelir. Böylece piyasa, rasyonel yatırımcı aracılığı ile, fiyatları teorik (içsel) değere doğru iter (Friedman, 1953:177). Sonuç olarak geleneksel finans, rasyonel yatırımcının halka açık olan bütün bilgiyi doğru ve eksiksiz kullanarak, Bayes kuralları çerçevesinde, belirli bir riske göre getirisini maksimize edeceğini ve yatırım kararlarını buna göre vereceğini söyler (Clark-Murphy ve Soutar, 2004: 540).

\section{DAVRANIŞSAL FINANS VE ARGÜMANLARI}

Davranışsal finans, literatürü 30 yılı aşkın bir süre domine eden Etkin Piyasa Hipotezi'ne ve dolayısı ile Beklenen Fayda Teorisi'ne birçok kereler meydan okumuş ve piyasa anomalilerini anlamaya çalışmıştır. Davranışsal Finans, Psikoloji ve Sosyoloji gibi bilim dallarından faydalanarak insanın yüzde yüz rasyonel bir varlık olmadığını, çeşitli bilişsel önyargılarının (cognitive bias) olabileceğini, ve sınırlı bilgi ve kapasite ile her daim optimum kararı veremeyeceğini savunur. Ana olarak kısıtlı arbitraj ve psikoloji ile temellendirilen bu argümanlar piyasa anomalilerini ve yatıımcı davranışlarındaki rasyonellikten uzak tutumları açıklamaya çalışmıştır.

Kahneman ve Tversky'nin 1979 yllındaki "Prospect Theory: Decision-making under risk" çalışması ile ortaya konulan beklenti teorisi, uzun yıllardır birçok İktisat ve finans teorisine temel olan beklenen fayda teorisine meydan okuyarak bu alandaki ilk adımları atmıştır. Klasik finans teorilerinin açıklamada yetersiz kaldığı piyasa anomalileri de bilimsel çalı̧̧malarla ortaya konulunca (bknz: Shefrin, 2002; Shleifer, 2000; French ve Roll, 1986; Ito vd., 1998; Karrh, 2004; Wärneryd, 2001, vb.) bu anomalileri açılayacak ve/veya anlayacak yeni yaklaşımlar geliştirilmeye çalışılmıştır.

$\mathrm{Bu}$ anomalilere en güçlü örnek, literatürde Hisse Senedi Primi Bilmecesi (Equity Premium Puzzle) olarak bilinen sermaye piyasalarındaki bonolara kıyasla aşırı risk pirimidir (Mehra ve Prescott, 1985: 145). Bu pirim klasik fiyatlama modelleriyle açıklanamayacak kadar büyük bir pirim olup bir anomali olarak karşımıza çıkar. Bunun yanında forex piyasalarındaki özel bilginin oynaklığa olan anlamlı etkisi (French ve Roll, 1986: 5; Ito vd. 
1998: 1111) de bir başka anomali olarak gösterilebilir. Bunun yanında bireysel yatırımcı davranışlarında da rasyonaliteden sapmalar gözlemlenmiştir. Mesela yatırımcıların kazanan hisse senetlerini hemen elden çıkarmaları ve kaybedenleri ise tutmaya devam etmeleri, bireylerin kendilerine olan aşırı güvenden kaynaklı yoğun bir şekilde piyasada pozisyon değiştirmeleri, alım satım yapmaları ve yüksek işlem masraflarına maruz kalmaları gibi.

Davranışsal finans gözlemlenen bu anomalileri sadece tespit etmekle kalmamış, bunlara açıklamalar getirmeye çalışmışır. Shefrin, davranışsal finansın temel mesajını "insanlar bilgiyi kullanmakta kusursuz değildir ve birçok yanılsama, hata ve algısal illüzyona maruz kalırlar" (Shefrin, 2002:10) diyerek özetlemiştir. Bu yanılsamalar ve bunlara açıklama olarak sunulan argümanları, Barberis ve Thaler, kısıtlı arbitraj ve psikolojik faktörler başlıklarıyla iki ana kısımda toplar.

\subsection{Kisitlı Arbitraj}

"Kısıtlı Arbitraj" savı piyasaların kusursuz olmadığını, dolayısı ile arbitraj stratejilerinin tamamen masrafsız ve risksiz olmadığını söyler (Shleifer ve Vishny, 1997: 35; Barberis ve Thaler, 2003: 1057). Yani, tanımı itibari ile risk ve ilk yatırım içermemesi gereken arbitraj firsatları gerçek hayatta aslında bu ikisini de içerebilirler. Böylelikle, yanlış fiyatlamayı gören profesyonel yatırımcılar bile bu firsatları değerlendirmekten imtina edebilirler. Kaldı ki, yatırımın temel analizler kullanmaktan ziyade söylentiler ve kulaktan dolma bilgiler ile yapan ve söylenti yatırımcı (noise trader) diye tabir edilen yatırımcılar, piyasadaki yanlış fiyatlamanın devamına neden olacak çoğunlukta olabilirler (Söylenti Yatırımcı Riski: Noise Trader Risk). Bu durumda, kısa vadede geri döndürülemeyecek olan yanlış fiyatlama, arbitrajdan faydalanmak isteyen yatırımcıyı zarara uğratabilir (De Long vd.,1990: 703). Sonuç olarak, arbitraj firsatlarını değerlendirip piyasadaki yanlış fiyatlamayı düzelteceğini düşündüğümüz rasyonel yatırımcılar yukarıda saydığımız sebeplerden ötürü çekimser olabilirler. Bu da bizi davranışsal finansın en temel iki savından biri olan arbitrajın gerçek piyasalarda kısıtlı olduğu gerçeğiyle yüzleştirir.

\subsection{Psikolojik Faktörler}

Bunun yanında, yatırımcıların tamamen rasyonel olmadıklarını ve yatırım kararı alırken çeşitli duygusal ve psikolojik faktörlerden etkilenebildikleri de literatürde defalarca çalışılmış ve gösterilmiştir. Kahnemann ve Tversky'nin karar alma literatüründe yaptı̆̆ önemli çalışmalarla, özellikle kompleks kararlarda bireylerin karar verme sürecini kolaylaştıracak zihinsel kısa yollar (hevristikler) kullanmaya eğilimli oldukları tartışılmıştır (Tversky ve Kahneman, 1974; 1124; Kahneman ve Frederick, 2002: 57). Ayrıca, geleneksel finansın öngördüğünün aksine, yatırımcıların - özellikle risk içeren kararlarda- tutarsız kararlar verebildikleri de gösterilmiş̧ir (Bessette vd., 2019: 11). Yatırım kararı da analiz gerektiren kompleks bir karar olması sebebiyle bu sınıflandırmaya giren ve zihinsel kisa yollar kullanmaya, dolayısı ile bazı önyargılardan etkilenmeye müsait olan kararlardandır (Ackert ve Deaves, 2009: 137). Bu kisa yollar literatürde hevristik (heuristic) diye tabir edilmiştir. 


\subsubsection{Zihinsel Kısa Yollar (Hevristikler)}

En öne çıkan zihinsel kısa yollar; Temsililik (Representativeness), Ulaşılabilirlik (Availability) ve Çıpalama Hevristiğidir (Anchoring). Finansal kararlarda da etkili olan bu hevristikler yatırımcıların optimum karardan sapmasına neden olabilirler. Örnek olarak, yatırımcıların temsililik hevristiğini kullanarak, kaliteli ürünler üreten ve yakın zamanda iyi getiri sağlamış firmaları pozitif değerlendirmeleri ve yatırım için iyi bir alternatif olarak düşünmeleri verilebilir (Chen vd., 2007: 425). Yine benzer bir mantıkla, yatırımcının ulaşılabilirlik hevristiğini kullanarak tanıdığı ve bildiği piyasalarda (Shiller, 1998: 1329) veya en kolay hatırladığı ve kendisine aşina gelen hisse senetlerine (Barber ve Odean, 2008: 813) yatıım yapmayı tercih etmeleri de bir diğer örnek olabilir. Son olarak, bir hisse senedinin fiyatının kısa süre içinde düşmesi sonucunda, yatırımcıların dayanak noktası (çıpalama noktası) olarak en son yüksek fiyatı alıp fiyatın tekrar yükseleceği beklentisine girmeleri ve bunu bir firsat olarak değerlendirerek o hisse senedine yatırım yapmayı tercih etmeleri de çıpalama hevristiğinin bir sonucu olarak gösterilebilir.

\subsubsection{Bilişsel Önyargılar}

Görüldüğü üzere bireysel yatırımlarda, rasyonel beklentiler teorisinin öngördüğü risk ve getiriye göre verilen optimum kararın aksine, bazı zihinsel kısa yolların etkisiyle rasyonellikten sapmalar tespit edilmiştir. Esasında, karar alma sürecine etkinlik ve fonksiyonellik açısından olumlu katkı sağlayan birer araç olarak da nitelendirilen bu zihinsel kısa yollar, her daim fonksiyonel olmayıp bazı bilişsel önyargılara (cognitive bias) da neden olabilmektedir. Literatürde ağırlıkla üzerinde durulan önyargılardan bazıları Aşırı Güven Önyargısı (Overconfidence Bias), Yatkınlık Etkisi (Disposition Effect), Kayıptan Kaçınma (Loss Aversion), Pişmanlılktan Kaçınma (Regret Aversion), Temsililik Önyargısı (Representativeness Bias), Ulaşılabilirlik Önyargısı (Availability Bias) ve Çıpalama Önyarıgısı (Anchoring Bias)'dır.

"Aşırı Güven Önyargısı", bireylerin kendi yetenek, bilgi birikimi ve kapasitelerini çevreye göre daha yüksek olarak değerlendirmesinden kaynaklanır (Odean, 1999: 1279). Yatırımcı kendi yatırımının performansından emin olur. Aşırı özgüvenli bireyler kendilerini ortalamanın üstünde görürler ve bilgi eksikliklerini görmezden gelerek karar alırlar. Bunun sonucunda özellikle finansal piyasalarda fazlaca pozisyon değiştirerek işlem maliyetlerinin artmasina sebep olurlar (bknz: Odean, 1999: 1296; Glaser ve Weber, 2003: 29 ; Statman vd., 2006: 1531). Bir diğer önyarg1, "Yatkınlık Etkisi" diye tabir edilen, yatırımcıların kazanan hisse senetlerini görece çabuk satmaya kaybedenleri de görece uzun tutmaya eğilimli olmalarıdır (Shefrin ve Statman, 1985: 777). Bailey, Kumar ve Ng (2011: 25) bireysel yatırımcıların; Odean (1998: 1775) ve Frazzini (2006: 2039) çalışmaları da hem bireysel yatırımcıların hem de yatırım ortaklıklarının bu etkiye paralel hareket ettiklerini göstermiştir. $\mathrm{Bu}$ davranışın sebebi; yatırımcıların kazançları bir an önce elde etmek isteyip kayıpları ise tahakkuk etmekte isteksiz olmalarıdır. Fakat yatırımın yeterince düşük bir Sharpe rasyosuna sahip olması durumunda, yatırımcının kayıpta olan yatırımını satabileceği de literatürde gösterilmiştir (Henderson, 2012: 458). "Kayıptan Kaçınma", bireylerin kazançlardansa kayıplara karşı daha duyarlı olması durumudur (Tversky ve Kahnemann, 1991: 1039). Sonuç olarak, yatırımcılar zararda olan yatırım pozisyonlarını, o zarardan kaçındıkları için, temel analizlerin öngördüğünden daha fazla tutma eğiliminde olabilirler. Bunun yanında, "Pişmanlıktan Kaçınma", kişinin gerçekte verdiği kararın sonucu ile vermediği kararın olası 
sonucunu karşılaştırmasından ortaya çıkar. Eğer olası sonuç gerçekleşenden iyiyse birey pişmanlık hisseder. Dolayısı ile, bir anlamda, 'bir tercihin faydası tercih edilmeyen seçeneğin olası sonuçlarının sebep olduğu duygulara bağlıdır' (Zeelenberg vd., 1996: 150). "Temsililik Önyargısı", temsililik hevristiğinin direk sonucudur ve yeni karşılaşılan olayların geçmişteki deneyimlerle oluşturulan sınıflandırmalara göre değerlendirilmesinden kaynaklanır. Esasında geçmiş performans gelecek performans için bir kriter değilken, yatırımcıların geçmişte iyi getiri sunmuş yatırım araçlarını iyi bir yatırım alternatifi olarak değerlendirmeleri bu önyargının bir sonucudur (Kumar ve Dhar, 2001: 5). Benzer şekilde "Ulaşılabilirlik Önyargısı"da aynı isimle anılan hevristiğin direk bir sonucudur ve bireylerin karar alırken ilk akla gelen deneyimlerinden faydalanmalarından kaynaklanmaktadır (Kahneman ve Tversky, 1972: 431). Buna örnek olarak finansal analistlerin şirketlerin hisse başına kazançlarını değerlendirirken, ekonominin genel gidişatı iyiyse olumlu değilse olumsuz değerlendirmede bulunmaları verilebilir (Lee vd., 2008: 172). Son olarak "Çıpalama Önyargısı" da yine aynı isimle anılan Çıpalama Hevristiğinin sonucudur ve bireylerin karar alırken Beklenen Fayda Teorisinin önerdiğinin aksine bir referans noktasını baz alarak değerlendirme yapmalarıyla ortaya çıkar. Bu referans noktasına fazlasıyla bağlı kalma, irrasyonel kararlara sebebiyet verebilir (Tversky ve Kahneman, 1974: 1128).

\section{DUYGU HEVRISTIĞĬI VE YATIRIM KARARINA ETKİSI}

Yukarıda bahsi geçen zihinsel kısa yollar, önyargılar ve bunlara bağlı ortaya çıkan irrasyonel kararlar literatürde yoğunlukla çalışılmıştır. Bunlar genellikle bilişsel önyargı ve yanılsamalar olup, kişinin bilgiyi analiz etmekteki yetersizliği, eksikliği veya aceleciliğinden ortaya çıkar. Bunun yanında, duyguların sebep olduğu irrasyonel kararlar da vardır. Psikoloji literatüründen türemiş, farklı disiplinlerde de ciddi çalışmalara konu olmuş olan duygu hevristiği (affect heuristic) ve buna bağlı ortaya çıkan irrasyonel finansal kararlar, nispeten bakir bir alan olup yeni gelişmelere açıktır.

Duygu hevristiği, bireylerin bir uyarana karşı hissettiği iyi veya kötü duygularından etkilenerek karar verme eğilimidir (Slovic vd., 2002: 330). Esasında psikoloji alanında yapılan çalışmalarda bireylerin karar vermelerinde duyguların önemi ve yeri, özellikle Çift Süreç Teorisi (Dual Process Theory. Detaylı bilgi için bknz: William James, 1890) çalışmalarında sıklıkla çizilmiş ve duyguların ilk ve hızlı karar vermede merkezi bir yeri olduğu vurgulanmıştır. Buna göre, bireyler her kararında birbirine paralel olarak çalışan, zaman zaman birinin diğerini ekarte ettiği iki sistemle ilerlerler; duygusal (deneyimsel) ve mantıksal (analitik) sistem. Daha hızlı ve pratik olması sebebiyle, özellikle karmaşı kararlarda ve belirsizlik içeren durumlarda, duygusal sistemin daha etkin olarak kullanıldığ öne sürülmüştür (Epstein, 1994: 709). Hatta, psikoloji alanında çalışmalar yapan Zajonc, daha da ileri giderek, insanoğlunun her algısında muhakkak bir duygu boyutu olduğunu ve bir uyarana karşı ilk reaksiyonun genellikle duygusal sistemden çıkan reaksiyon olduğunu savunmuştur (Zajonc, 1980: 154). Duyguların karar verme mekanizması üzerindeki etkileri psikoloji alanında birçok çalışmaya konu olmuştur ve oradan karar verme, pazarlama ve sonrasında finans literatürlerine transfer edilmiştir. Nobel Ödülü sahibi bilim insanı Daniel Kahneman, duygu hevristiği için son yllarda karar verme literatüründeki en önemli gelişmelerden biri değerlendirmesinde bulunmuştur. Buna mukabil, duyguların finansal kararlar üzerindeki etkisi ve bunun yatırımcılar ve piyasalar açısından sonuçları henüz yeteri ölçüde çalışılmamıştır. Bu çalışmada, duygu hevristiği ve finansal kararlara olan etkisi 
üzerine yeni çalışmaların desteklemesi, böylelikle yatırımcıların irrasyonel davranışlarının bu açıdan da değerlendirilerek daha iyi anlaşılması amaçlanmıştır.

Yatırımcı duyarlılığı ile ilgili ciddi çalışmaları olan Meir Statman, yatırım kararını sadece risk ve getiriden ibaret görmenin, romantik bir akşam yemeğini sadece besin değerleriyle değerlendirmek gibi olduğunu söyleyerek bunun insan doğasına aykırı olduğunu vurgulamıştır. Ayrıca yatııım kararı birçok değişkeni ve bilinmeyeni barındıran kompleks bir karardır. Bütün piyasa bilgisine sahip olmayan ve bu bilgiyi kusursuz işleyecek bilgi ve donanıma sahip olamayan yatırımcıların, bu kararı vermek için kısıtlı bir zamanları vardır. Bunun gibi bilginin, kapasitenin ve zamanın kısıtlı olduğu, bir bilinmezlik faktörü de içeren kompleks ve risk içeren kararlarda duygu hevristiğinin ilk reaksiyonda belirleyici olduğu gösterilmiştir (Loewenstein vd., 2001: 272; Mellers, 2000: 917). Dolayısı ile, yatıım kararı insanın duygularından, hissiyatından izole bir karar değildir ve risk ve getiri dışında duygusal değerlendirmelerden de etkilenebilir. Araştırmacılar, özellikle 2000'li yllar itibari ile, duygusal faktörlerin duygu hevristiği aracılı̆̆ 1 ile yatırım kararına olan etkisini ciddi çalışmalara konu edinmişlerdir (bknz: Slovic vd., 2002, 2007; Finucane vd., 2000; MacGregor vd., 2000).

Shefrin (2005) davranışsal finans perspektifinden faizlerin vade yapısını çalışmış ve yatırımcıların duyarlılığını da içeren bir stokastik iskonto faktörü öne sürmüştür. Yaptı̆̆ı testlerde ise bu faktörün istatistiksel olarak anlamlı olduğunu göstermiştir (Shefrin, 2005: 230). Bu da yatırım kararında risk ve getiri dışında başka faktörlerin de dikkate alındığının bir göstergesidir. Bunu yanısıra, Shefrin ve Statman (2000: 149) ortaya koydukları davranışsal portföy teorisi ile yatırımcıların irrasyonel tutumlarını içeren bir model oluşturmuşlar ve buradan ortaya çıkan optimum portföyün geleneksel markowitz optimum portföyüyle çok net ayrıştığını göstermişlerdir. Böylelikle geleneksel fiyatlama teorilerinde hiçbir etki atfedilmeyen "duyarll1lk" (sentiment) veya "duygu" (affect) nun risk primini etkilediği gösterilmiştir. Daha sonrasında, yine Statman, Fisher ve Anginer ile beraber, bireysel yatırımcılarla yaptıkları anket çalışmasında yatırımcıların bazı hisse senetlerini olumlu bazılarını ise olumsuz duygularla bağdaştırdıklarını bulmuşlardır. Aynı yatırımcılar, olumlu olarak değerlendirdikleri hisse senetlerinden yüksek getiri düşük risk beklerken olumsuz olarak değerlendirdikleri hisse senetlerinden düş̧ük getiri ve yüksek risk beklediklerini ifade etmişlerdir (Statman vd., 2008: 25). Bu risk ve getiri değerlendirmeleri geleneksel finansın önermesiyle taban tabana zıttır ve bunun en temel sebebi yatırımciların şirketlerle ilgili duygusal değerlendirmelerinden etkilenmeleridir. Bu çalışmaya paralel olarak, Ang, Chua ve Jiang (2010:52), aynı şirketin A sınıfı hisse senetlerinin B sınıfı hisse senetlerinden daha üst sınıf olarak görülüp yatırımcı tarafindan daha kıymetli olarak değerlendirilmesi sonucunu sunmuştur. Bu değerlendirme sadece hisse senedinin adındaki A ve B ibarelerinin yatırımcıda iyi/tercih edilen veya kötü/tercih edilmeyen algısını oluşturmasından kaynaklanmaktadır.

Literatürde bir kısım çalışmalar da psikolojinin yanına pazarlama literatürünü de ekleyerek marka, kurumsal kimlik, marka sadakati ve algısı ile yatırım davranışlarının ilişsisini incelemiştir. Marka algısının hisse senedi yatırımı üzerine etkisini araştıran Freider ve Subrahmanyam (2005: 81), bireysel yatırımcıların "sevilen" ve tüketici bilinirliği yüksek markaların kağıtlarına yatırım yaptıklarını göstererek duygusal değerlendirmelerin önemine dikkat çekmiştir. Bir adım ileri giderek, marka sadakati ile hisse senedi yatırımı arasındaki olumlu ilişki de literatürde yapılan çalışmalarla gözler önüne serilmiştir. Buna göre, markalara olan sadakat hisse senedi yatırımını, hisse senedi yatırımı da markaya olan 
düşkünlüğü olumlu yönde etkilemektedir (Schoenbachler vd., 2004: 495; Aspara vd., 2008: 157). Aaker ve Jacobson (1994: 200) ve Lane ve Jacobson (1995: 74) çalışmaları da marka ve şirketin kurumsal algısının, direk olarak yatırım kararı ile olmasa da, hisse senedi değeri ile ilişkisini ortaya koymuşlardır.

$\mathrm{Bu}$ çalışmalar duygusal değerlendirmelerin yatırım kararına etkisini göstermeleri bakımından önemlidir. Fakat bunlara ek olarak, duyguların ekstra bir yatırım motivasyonu olarak ortaya çıktığını gösteren çalışmalar, duygu hevristiğinin finansal kararlara etkisinin düşündügü̈müzden fazla olabileceğini bizlere göstermiştir. Aspara ve Tikkanen'in, ürün ve şirket üzerine olan genel değerlendirmelerin hisse senedi seçimi üzerine etkisini gösteren, 2010a, 2010b, 2011b tarihli çalı̧maları bunlardan bazılarıdır. Duygusal yatııım motivasyonlarını çalışan Aspara ve Tikkanen, Finli bireysel yatırımcılar üzerine yaptıkları anket çalışması aracılığıyla, ekstra bir duygusal yatırım motivasyonunun varlığını göstermiş ve bireysel yatırımcıların rasyonellikten saparak sadece risk ve getiri temelli değil, bunun yanında duygusal temelli yatırım kararı verdiklerini göstermişlerdir (Aspara ve Tikkanen, 2011a: 84). Bu literatürün devamı niteliğinde olan bir çalışma da Usul, Özdemir ve Kiessling'den 2017 yılında gelmiştir. Usul ve diğerleri sundukları teorik modelle, duygu hevristiğinin yatırım kararına etkisini modellemişlerdir. Yatırımcıların şirketlerle kurdukları duygusal bağların yatırım motivasyonlarını arttırdığını iddia etmişler ve Türkiye'deki aktif bireysel hisse senedi yatırımcıları üzerinde yaptıkları anket çalışması ile bunu ampirik olarak test etmişlerdir. Sonuçlar, yatırımcıların, sosyal sorumluluk bilinci veya milliyetçilik gibi duyguların yatııım motivasyonu üzerine anlamlı ve pozitif etkisini ortaya koymuştur (Usul vd., 2017: 104). Bu çalışma ile, sosyal sorumlu yatırım (socially responsible investment) fikrinin ve yerli varlıklara yatırım önyargısının (home bias) yatırımcıyı duygusal olarak etkilediği ve finansal göstergelerin üzerinde bir yatırım motivasyonuna sebep olduğu gösterilmiştir. Buradan da anlaşılacağı üzere, yatırımcı davranışlarını ve psikolojisini daha iyi tahlil edebilmek için farklı disiplinlerden destek almak, ve disiplinler arası bir bakış açısıyla hareket etmek yeni ufuklar açacaktır.

\section{SONUÇ VE TARTIŞMA}

Sonuç olarak, finansal kararlar kompleks ve bilinmezlik içeren kararlardır. Yatırımcıların kararları da her zaman duygu, düşünce ve deneyimlerden izole, yansız ve optimum kararlar değillerdir. Dolayısı ile, çeşitli önyargı ve irrasyonelliğe maruz kalabilir. Bu çalışma ile, hem genel olarak bu önyargı ve yanılsamaların hem de duygu hevristiği aracılığı ile duyguların yatırım kararları üzerine etkileri tartışılmıştır. Duygu hevristiği ve duyguların finansal kararlar üzerindeki rolü, özellikle son y1llarda dikkatleri üzerine çeken kavramlar olup, henüz yeteri kadar çalışmanın yapılmadığı alanlardır. Geleneksel finansa tamamlayıcı bir dal olarak ortaya çıkan davranışsal finans, içerisindeki diğer hevristik ve önyargılarla beraber, finansal yatırım kararındaki irrasyonellikleri anlamakta araştırmacılara yeni bir yol sunmaktadır.

Hali hazırda davranışsal finans literatürü, sunduğu anomaliler ve bunlara getirdiği açıklamalarla, risk ve beklenen getirinin yatırımcıların davranışlarını açıklamakta tek başlarına yetersiz kaldığını ortaya koymaktadır. Fakat duygu hevristiği, görece yeni bir kavram olup, yatırım kararı üzerine olan etkileri tam ve yeterli ölçüde araştırılmamıştır. Bu alanda hem farklı ekonomilerde (gelişmiş/gelişmekte olan), hem farklı piyasalarda (hisse senedi, gayri menkul, türev), hem de farklı hedef kitle ile (profesyonel/bireysel yatırımcı) 
yapılacak çalışmalara ihtiyaç vardır. Bu çalışmada sunulan literatür taramasının, duygu hevristiği ve bunun finansal kararlarla olan etkileşimi alanında yeni çalışmaları destekleyerek finansal yatırım sürecindeki irrasyonel tutum ve davranışların daha iyi anlaşılmasına katkı sağlayacağ 1 umulmaktadır.

\section{KAYNAKLAR}

Aaker, David A. - Jacobson, Robert (1994), “The Financial Information Content of Perceived Quality”, Journal of Marketing Research, 31, pp. 191-201.

Ackert, Lucy - Deaves, Richard (2009), Behavioral Finance: Psychology, Decision-making and Markets, Cengage Learning, Ohaio.

Ang, James - Chua, Ansley - Jiang, Danling (2010), "Is A better than B? How Affect Influences the Marketing and Pricing of Financial Securities", Financial Analysts Journal, 66, pp. 40-54.

Aspara, Jaakko - Nyman, Henrich -Tikkanen, Henrikki (2008), "Influence of Share Ownership in Repeat Patronage”, Journal of Consumer Behavior, 7(2), pp. 149-163.

Aspara, Jaakko - Tikkanen, Henrikki (2010a), "Consumers' Stock Preferences Beyond Expected Financial Returns: The Influence of Product and Brand Evaluations", International Journal of Bank Marketing, 28, pp. 193-221.

Aspara, Jaakko - Tikkanen, Henrikki (2010b), "The Role of Company Affect in Stock Investments: Towards Blind, Undemanding, Non-comparative, and Committed Love", Journal of Behavioral Finance, 11, pp. 103-113.

Aspara, Jaakko - Tikkanen, Henrikki (2011a), "Individuals' Affect-based Motivations to Invest in Stocks: Beyond Expected Financial Returns and Risks", Journal of Behavioral Finance, 12(2), pp. 78-89.

Aspara, Jaakko - Tikkanen, Henrikki (2011b), "Corporate Marketing in the Stock Market: The Impact of Company Identification on Individuals' Investment Behavior", European Journal of Marketing, 45(9/10), pp. 1446-1469.

Aytekin, Y. Emre - Aygün, Mehmet (2016), "Finansta Yeni Bir Alan: Davranışsal Finans", Van Yüzüncü Y1l Üniversitesi İktisadi Ve İdari Bilimler Fakültesi Dergisi, 2, ss. 143156.

Bailey, Warren - Kumar, Alok - Ng, David (2011), "Behavioral Biases of Mutual Fund Investors", Journal of Financial Economics, 102, pp. 1-27.

Barber, Brad M. - Odean, Terrance (2008), "All That Glitters: The Effect of Attention and News on the Buying Behavior of Individual and Institutional Investors", Review of Financial Studies, 21(2), pp. 785-818. 
Barberis, Nicholas - Thaler, Richard (2003), "A Survey of Behavioral Finance”, In Constantinides, George M. - Harris, Milton - Stulz, Rene M. (Ed.), Handbook of the Economics of Finance (1B), Elsevier, North Holland, pp. 1053-1123.

Bayazıt Hayta, Ateş (2014), "Bireysel Yatirimcilarin Finansal Risk Algisina Etki Eden Psikolojik Önyargilar”, Türkiye Sosyal Araştırmalar Dergisi, 183, ss. 329-352.

Bessette, Douglas L.- Wilson, Robyn S.- Arvai, Joseph L. (2019), "Do people disagree with themselves? Exploring the internal consistency of complex, unfamiliar, and risky decisions", Journal of Risk Research, pp. 1-13.

Chen, Gong-Meng - Kim, Kenneth A. - Nofsinger, John R. - Rui, Oliver M. (2007), “Trading Performance, Disposition Effect, Overconfidence, Representativeness Bias, and Experience of Emerging Market Investors", Journal of Behavioral Decision Making, 20(4), pp. 425-451.

Clark-Murphy, Marilyn - Soutar, Geoffrey N. (2004), "What Individual Investors Value: Some Australian Evidence", Journal of Economic Psychology, 25(4), pp. 539-555.

De Long, J. Bradford - Shleifer, Andrei - Summers, Lawrence H. - Waldmann, Robert J. (1990), "Noise Trader Risk in Financial Markets", Journal of Political Economy, 98(4), pp. 703-738.

Epstein, Seymour (1994), "Integration of the Cognitive and the Psychodynamic Unconscious", American Psychologist, 49(8), pp. 709-724.

Fama, Eugene (1970), "Efficient Capital Markets: A Review of Theory and Empirical Work", The Journal of Finance, 25(2), pp. 383-417.

Finucane, Melissa L. - Alhakami, Ali - Slovic, Paul - Johnson, Stephen M. (2000), "The Affect Heuristic in Judgments of Risks and Benefits", Journal of Behavioral Decision Making, 13, pp. 1-17.

Frazzini, Andrea (2006), "The Disposition Effect and Underreaction to News", The Journal of Finance, 61(4), pp. 2017-2046.

French, Kenneth - Roll, Richard (1986), "Stock Return Variances: The Arrival of Information and the Reaction of Traders", Journal of Financial Economics, 17(1), pp. 5-26.

Frieder, Laura - Subrahmanyam, Avanidhar (2005), "Brand Perceptions and the Market for Common Stock", Journal of Financial and Quantitative Analysis, 40, pp. 57-85.

Friedman, Milton (1953), Essays in Positive Economics, University of Chicago Press, Chicago.

Glaser, Marcus - Weber, Martin (2007), "Overconfidence and Trading Volume”, Geneva Risk and Insurance Review, 32(1), pp. 1-36. 
Henderson, Vicky (2012), "Prospect Theory, Liquidation, and the Disposition Effect", Management Science, 58(2), pp. 445-460.

Ito, Takatoshi - Lyons, Richard K. - Melvin, Michael T. (1998), "Is There Private Information in the FX Market? The Tokyo Experiment", The Journal of Finance, 53, pp. 11111130.

Kahneman, Daniel - Frederick, Shane (2002), "Representativeness Revisited: Attribute Substitution in Intuitive Judgment", In Gilovich, Thomas - Griffin, Dale - Kahneman, Daniel (Eds.), Heuristics and Biases: The Psychology of Intuitive Judgment, Cambridge University Press, Cambridge, UK, pp. 49-82.

Kahneman, Daniel - Tversky, Amos (1972), "Subjective Probability: A Judgment of Representativeness", Cognitive Psychology, 3, pp. 430-454.

Kahneman, Daniel - Tversky, Amos (1979), Prospect Theory: An Analysis of Decision Under Risk", Econometrica, 47(2), pp. 263-91.

Kahyaoğlu, Mehmet Burak (2011), "Yatırım Kararlarına Etki Eden Çeşitli Duygusal ve Psikolojik Faktörlere Maruz Kalma Düzeyi Üzerinde Cinsiyetin Rolü: İMKB Bireysel Hisse Senedi Yatırımcıları Üzerine Bir Uygulama”, Ekonomik ve Sosyal Araştırmalar Degisi, 7(1), ss.29-51.

Karrh, James A (2004), "Does advertising influence investors? Evidence and research propositions", Journal of Current Issues Research in Advertising, 26(2), pp. 1-10.

Kumar, Alok - Dhar, Ravi (2001), "A Non-Random Walk Down the Main Street: Impact of Price Trends on Trading Decisions of Individual Investors," Yale School of Management Working Papers ysm208, Yale School of Management.

Lane, Vicki - Jacobson, Robert (1995), "Stock Market Reactions to Brand Extension Announcements: The Effects of Brand Attitude and Familiarity", Journal of Marketing, 59(1), pp. 63-77.

Lee, Byung Hwan - O’Brien, John - Sivaramakrishnan, Kalyanakrishnan (2008), “An Analysis of Financial Analysts Optimism in Long-term Growth Forecasts", Journal of Behavioral Finance, 9(3), pp. 171-184.

Lintner, John (1965), "The Valuation of Risk Assets and the Selection of Risky Investments in Stock Portfolios and Capital Budgets", The Review of Economics and Statistics,47(1), pp. 13-37.

Loewenstein, George F. - Weber, Elke U. - Hsee, Cristopher K. - Welch, Ned (2001), "Risk as Feelings", Psychological Bulletin, 127(2), pp. 267-286.

Macgregor, Donald G. - Slovic, Paul - Dreman, David - Berry, Micheal (2000), "Imagery, Affect, and Financial Judgment", The Journal of Psychology and Financial Markets, 1(2), pp. 104-110. 
Mehra, Rajnish - Prescott, Edward (1985), "The Equity Premium: A Puzzle", Journal of Monetary Economics, 15(2), pp. 145-161.

Mcfadden, Daniel - Machina, Mark J. - Baron, Jonathan (1999), Rationality for Economists? In Fischhoff, Baruch - Manski, Charles F., Elicitation of Preferences, Springer, Netherlands, pp. 73-110.

Mellers, Barbara A. (2000), "Choice and the Relative Pleasure of Consequences", Psychological Bulletin, 26(6), pp. 910-924.

Odean, Terrance (1998), “Are Investors Reluctant to Realize Their Losses?”, The Journal of Finance, 53(5), pp. 1775-1798.

Odean, Terrance (1999), “Do Investors Trade Too Much?”, American Economic Review, 89, pp. $1279-1298$.

Onur, Sara - Kırıkcı, Süreyya (2018), "Literatür İncelemesi: Planlı Davranış Teorisi ve Davranışsal İktisat”, International Social Studies Journal, 4(23), ss. 4534-4548.

Schoenbachler, Daniel D. - Gordon, Geoffrey L. - Aurand, Timothy W. (2004), "Building Brand Loyalty Through Individual Stock Ownership", Journal of Product \& Brand Management, 13(7), pp. 488-497.

Sezer, Durmuş - Demir, Sezgin (2015), "Finansal Yatırımcıların Okuryazarlık ve Blişsel Yetenek Düzeylerinin Psikolojik Yanılsamalar ile İlişkisi”, Muhasebe ve Finansman Dergisi, 66, ss. 69-88.

Sharpe, William (1963), "A Simplified Model for Portfolio Analysis", Management Science, 9(2), pp. 277-293.

Shefrin, Hersh (2002), Beyond Greed and Fear, Oxford University Press, UK.

Shefrin, Hersh (2005), A Behavioral Approach to Asset Pricing, First Edition, Elsevier Academic Press, Boston.

Shefrin, Hersh- Statman, Meir (2000), "Behavioral Portfolio Theory", The Journal of Financial and Quantitative Analysis, 35(2), pp. 127 -151.

Shiller, Robert J. (1998), "Human Behavior and the Efficiency of the Financial System", In Taylor, John B. - Woodford, Michael (Ed.), Handbook of Macroeconomics, 1, Elsevier, North Holland, pp. 1305-1340.

Shleifer, Andrei (2000), Inefficient Markets: An Introduction to Behavioural Finance, Oxford University Press, UK.

Shleifer, Andrei - Vishny, Robert W. (1997), "The Limits of Arbitrage", The Journal of Finance, 52(1), pp. 35-55. 
Slovic, Paul - Finucane, Melissa L. - Peters, Ellen - Macgregor, Donald G. (2002), "Rational Actors or Rational Fools: Implications of the Affect Heuristic for Behavioral Economics", Journal of Socio-Economics, 31, pp. 329-342.

Slovic, Paul - Finucane, Melissa L. - Peters, Ellen - Macgregor, Donald G. (2007), "The Affect Heuristic", European Journal of Operational Research, 177, pp. 1333-1352.

Simon, Herb A. (1986), "Rationality in Psychology and Economics", In Hogarth, Robin M. Reder, Melvin W. (Eds.), Rational Choice, The University of Chicago Press, Chicago, pp. 25-40.

Statman, Meir - Fisher, Kenneth L. - Anginer, Deniz (2008), Affect in a Behavioral Asset Pricing Model, Financial Analysts Journal, 64, pp. 20-29.

Statman, Meir - Thorley, Steven - Vorkink, Keith (2006), "Investor Overconfidence and Trading Volume”, Review of Financial Studies, 19(4), pp. 1531-1565.

Taner, Berna - Akkaya, G. Cenk (2005), "Yatırımcı Psikolojisi ve Davranışsal Finans Yaklaşımı", Muhasebe ve Finansman Dergisi, 27, ss. 47-54.

Tversky, Amos - Kahneman, Daniel (1974), "Judgement Under Uncertainty: Heuristics and Biases", Science, New Series, 185(4157), pp. 1124-1131.

Tversky, Amos - Kahneman, Daniel (1981), "The Framing of Decisions and the Psychology of Choice”, Science, 211(4481), pp. 453-458.

Tversky, Amos - Kahneman, Daniel (1991), "Loss Aversion in Riskless Choice: A ReferenceDependent Model”, The Quarterly Journal of Economics, 106 (4), pp. 1039-1061.

Usul, Naime - Özdemir, Özlem - Kiessling, Timothy (2017), “Affect-based Stock Investment Decision: The Role of Affective Self-affinity", Journal of Behavioral and Experimental Economics (formerly The Journal of Socio-Economics), 68, pp. 97-109.

Warneryd, Karl-Erik (2001), Stock-Market Psychology: How People Value and Trade Stocks, Edward Elgar, Cheltenham, UK.

William, James (1890), Principles of Psychology, Dover Publications.

Zajonc, Robert B. (1980), "Feeling and Thinking: Preferences Need No Inferences", American Psychologist, 35(2), pp. 151-175.

Zeelenberg, Marcel - Beattie, Jane - Van Der Pligt, Joop - De Vries, Nanne K. (1996), "Consequences of Regret Aversion: Effects of Expected Feedback on Risky Decision Making", Organizational Behavior and Human Decision Processes, 65(2), pp. 148158. 
